\title{
miR-183 functions as an oncogene by targeting ABCA1 in colon cancer
}

\author{
DA-PENG BI $^{1 *}$, CHENG-HUA YIN $^{1 *}$, XIAO-YUE ZHANG ${ }^{1}$, NA-NA YANG ${ }^{1}$ and JIA-YOU XU ${ }^{2}$ \\ ${ }^{1}$ The Second Department of Internal Medicine, Jinan Second People's Hospital, Jinan, Shandong 250001; \\ ${ }^{2}$ Department of General Surgery, Weifang People's Hospital, Weifang, Shandong 261041, P.R. China
}

Received September 5, 2015; Accepted October 13, 2015

DOI: 10.3892/or.2016.4631

\begin{abstract}
Colon cancer remains the second most common cause of cancer-related death, indicating that a proportion of cancer cells are not eradicated by current therapies. Investigation of the molecular mechanisms involved in the development and progression of the disease will aid in the further understanding of the pathogenesis and progression and offer new targets for effective therapies. In the present study, we initially confirmed that ABCA1 was aberrantly expressed in colon cancer tissues and colon cancer cells. Its overexpression inhibited the proliferation of colon cancer HCT116 cells while silencing of ABCA1 promoted the proliferation and inhibited the apoptosis of colon cancer LDL1 cells. Upregulation of specific miRNAs can contribute to the downregulation of tumor-suppressive genes. Thus, we aimed to ascertain whether ABCA1 is downregulated by overexpression of a specific miRNA in colon cancer. We screened microRNAs that may target ABCA1 by miRanda which is a commonly used prediction algorithm. We found that miR-183 targets the 3'UTR of ABCA1 mRNA. Subsequent experiments confirmed that miR-183 degraded ABCA1 mRNA in the colon cancer cells. Finally, we demonstrated that miR-183 promoted the proliferation and inhibited the apoptosis of colon cancer cells. Thus, we conclude that miR-183 promotes proliferation and inhibits apoptosis by degrading ABCA1 in colon cancer.
\end{abstract}

\section{Introduction}

Colorectal cancer is the third most common cancer worldwide and the second leading cause of cancer-related deaths (1). Elucidating the molecular mechanisms involved in the proliferation, migration and invasion of colorectal cancer not only will aid in the further understanding of the pathogenesis and

Correspondence to: Dr Jia-You Xu, Department of General Surgery, Weifang People's Hospital, 151 Guangwen Street, Kuiwen, Weifang, Shandong 261041, P.R. China

E-mail: xujiayou1041@sina.com

*Contributed equally

Key words: colon cancer, cholesterol, miR-183, ABCA1 progression of the disease, but may also elucidate new targets for effective therapies.

Aberrant regulation of cholesterol homeostasis has been associated with multiple types of cancer. Numerous studies have shown increased levels of cholesterol in tumors when compared to the level in normal tissue (2-7). Moreover, it has been suggested that cholesterol intake may increase colorectal cancer risk (8). Multiple pathways to increase intracellular cholesterol have been observed in various types of cancer cells. These include upregulation of 3-hydroxy-3-methylglutaryl CoA reductase (HMG-CoAR) activity, the rate-limiting step of the cholesterol synthesis pathway (9-11), loss of feedback inhibition of HMGCoAR by cholesterol (12-14), increased uptake of extracellular cholesterol through the low-density lipoprotein receptor (15-17), and decreased expression of the cholesterol exporter termed ATP-binding cassette transporter A1/cholesterol exporter (ABCA1) (16,18-20). The ABCA1 protein mediates the transfer of cellular cholesterol across the plasma membrane to apolipoprotein A-I (ApoAI), the major apolipoprotein component of high-density lipoprotein (HDL) (21). ABCA1 gene, a key player in cholesterol metabolism, prompted us to investigate its role in colon cancer.

MicroRNAs (miRNAs) are small, non-coding RNAs that post-transcriptionally regulate gene expression and play significant roles in maintaining normal cellular functions, including regulation of cholesterol homeostasis (22-26). Deregulation of miRNA expression leads to the onset of diverse types of diseases, including cancer as exemplified by their differential expression in carcinomas, sarcomas and hematologic tumors (27-31). miR-183 can function as an oncogene by targeting the transcription factor EGR1 and was found to promote cell migration in colon cancer (32). Yet, the mechanism remains unknown.

In the present study, we initially confirmed that ABCA1 is aberrantly expression in colon cancer and colon cancer cells. Its overexpression inhibited the proliferation of colon cancer HCT116 cells while the silencing of ABCA1 promoted proliferation and inhibited apoptosis in colon cancer LDL1 cells. Upregulation of specific miRNAs can contribute to downregulation of tumor-suppressive genes (33-35). Thus, we aimed to ascertain whether ABCA1 is downregulated by overexpression of a specific miRNA in colon cancer. We screened microRNAs that may target ABCA1 by miRanda which is a commonly used prediction algorithm. We found that miR-183 
targets the 3'UTR of ABCA1 mRNA. Subsequent experiments confirmed that miR-183 degraded ABCA1 mRNA in the colon cancer cells. Finally, we demonstrated that miR-183 promoted proliferation and inhibited apoptosis in the cells. Thus, we conclude that miR-183 promotes proliferation and inhibits apoptosis by regulating ABCA1 in colon cancer.

\section{Materials and methods}

Colon cancer tissues and colon cancer cell lines DLD1,Caco-2, HCT116, DiFi, Lim 1215 and HCA7. All colon cancer patients were recruited from the Jinan Second People's Hospital. The use of human tissue samples and research conducted on humans followed internationally recognized guidelines as well as local and national regulations. All participants provided informed consent. Colon cancer cell lines DLD1, Caco-2, HCT116, DiFi, Lim1215 and HCA7 were purchased from the Cell Bank of the Chinese Academy of Sciences (Shanghai, China). Cells were maintained in RPMI-1640 medium supplemented with $10 \%$ fetal bovine serum (FBS) (Gibco, Grand Island, NY, USA) and penicillin/streptomycin at $37^{\circ} \mathrm{C}$ in a humidified atmosphere with $5 \% \mathrm{CO}_{2}$.

ABCA1-expressing plasmids/empty vectors, shABCA1 plasmids/scramble, pre-miR-183/control miR, anti-miR-183/ scramble and transfection experiments. ABCA1-expressing plasmids/empty vector and shMRTF-A plasmids/scramble were obtained from Boston University (Boston, MA, USA). Pre-miR-183/control miR and anti-miR-183/scramble were purchased from Ambion Inc. (Austin, TX, USA). Before transfection, the cells were cultured in serum-free medium without antibiotics for $24 \mathrm{~h}$. On the following day, cells at $\sim 90 \%$ confluency were transfected with transfection reagent (Lipofectamine 2000; Invitrogen, Carlsbad, CA, USA), according to the manufacturer's instructions. After incubation for $6 \mathrm{~h}$, the medium was removed and replaced with normal culture medium for $48 \mathrm{~h}$.

Western blot analysis. Tissue and cell lysates, normalized for cell protein content, were analyzed by western blotting (36). Mainly, after incubation with the primary antibody: antiABCA1 (1:500), anti-c-myc (1:500), anti-p53 (1:500), anti-CDK2 (1:500), anti-p21 (1:500), anti-cyclin D1 (1:500), anti-BCL2 (1:500), anti-MCL1 (1:500) or anti- $\beta$-actin (1:500) (all from Abcam, Cambridge, MA, USA), the secondary antibodies were used to bind to the primary antibodies.

MTT assay. Cells were seeded in 96-well plates and divided into different groups. After treatment, $20 \mu \mathrm{l}$ MTT solution ( $5 \mathrm{mg} / \mathrm{ml}$; Sigma, St. Louis, MO, USA) was added to each well and incubated for $4 \mathrm{~h}$ at $37^{\circ} \mathrm{C}$. After that, the culture medium was removed and $150 \mu 1$ DMSO (Sigma) was added to each well. The absorbance was measured at $490 \mathrm{~nm}$.

Migration and invasion assays. Cells were transferred into the top chamber with a non-coated membrane at $5 \times 10^{4}$ cells/ well (24-well plate, pore size, $8.0 \mu \mathrm{m}$; BD Biosciences, San Jose, CA, USA) in the Transwell migration assay. For the Transwell invasion assay, $5 \times 10^{4}$ cells/well were plated in the top chamber with a Matrigel-coated membrane (24-well plate,
A

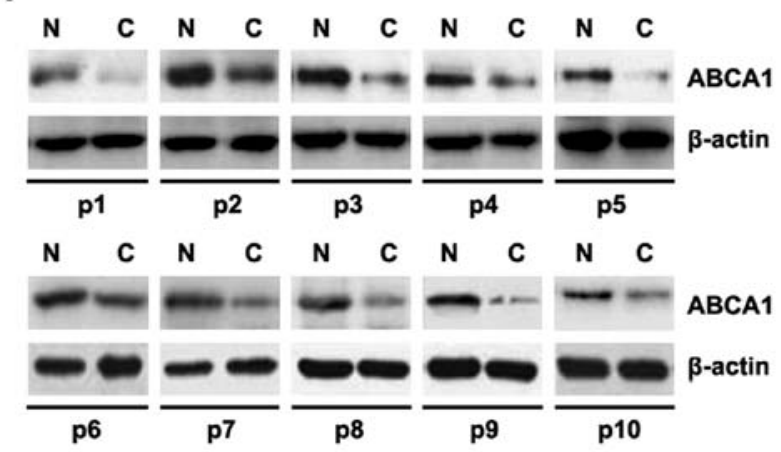

B

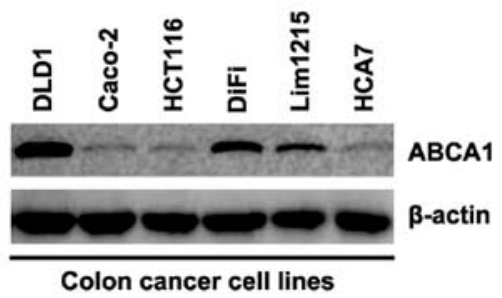

Figure 1. ABCA1 is aberrantly expressed in colon cancer tissues. (A) Western blotting for ABCA1 in colon cancer tissues (C) and adjacent normal tissues (N). Patients are numbered as p1-p10. All the 10 patients were diagnosed as having colon cancer. $\beta$-actin was used as a loading control; $\mathrm{n}=10$. (B) Western blotting for ABCA1 in colon cancer cell lines DLD1, Caco-2, HCT116, DiFi, Lim1215 and HCA7. $\beta$-actin was used as a loading control; $\mathrm{n}=3$.

pore size, $8.0 \mu \mathrm{m}$; BD Biosciences). In both assays, medium with $10 \%$ FBS was placed in the lower chamber, while cells were plated in medium without serum or growth factors in the upper chamber. After $24 \mathrm{~h}$ of incubation, the non-invading and non-migrating cells were removed by wiping the upper surface of the filter with a cotton swab. The remaining cells on the lower surface of the membrane were stained and counted.

Bioinformatic methods. Analysis of potential microRNA target sites was carried out using commonly used prediction algorithm, miRanda (http://www.microrna.org/microrna/ home.do).

Immunofluorescence analyses. Cells were plated onto coverslips in 6-well plates and transfected with $30 \mathrm{nM}$ pre-miR-183 or control miR. After transfection for $36 \mathrm{~h}$, the coverslips were stained with the anti-ABCA1 antibody. Anti-rabbit IgG antibody was used as the secondary antibody (Invitrogen). Coverslips were counterstained with DAPI (Invitrogen Molecular Probes, Eugene, OR, USA) for visualization of nuclei. Results were observed using a confocal laser scanning microscope (Leica Microsystems, Bensheim, Germany) and analyzed by Image J software.

$R T-P C R$ and $q R T-P C R$ for ABCA1. Total RNA was extracted from cells using TRIzol reagent (Invitrogen) according to the manufacturer's protocol. qRT-PCR was carried out with a Power SYBR Green PCR Master Mix (Applied Biosystems, Carlsbad, CA, USA) according to the manufacturer's instructions. The primers were: ABCA1 forward, 5'-TTAAACGCC CTCACCAAAGAC-3' and reverse, 5'-AAAAGCCGCCAT ACCTAAACTCAT-3'. 
A

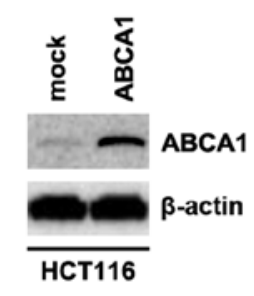

D

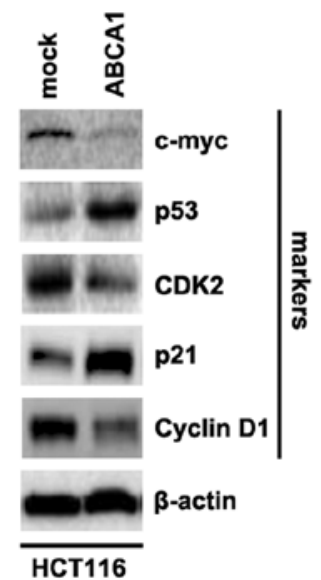

B

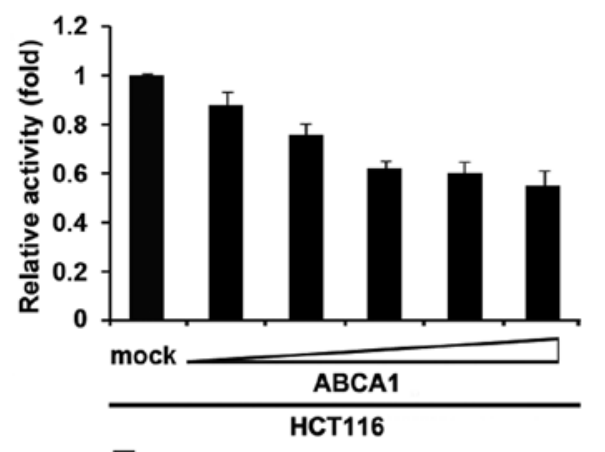

E

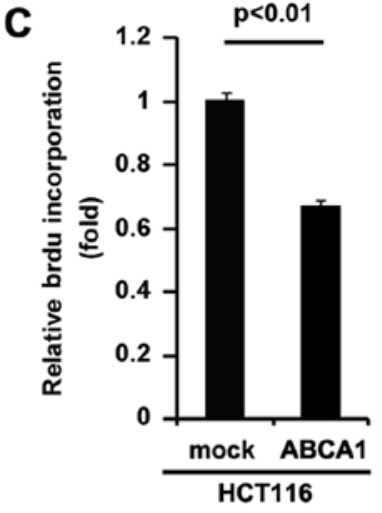

ABCA1 $p>0.05$

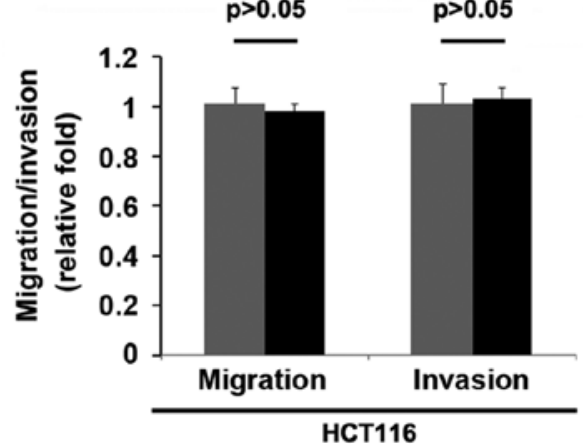

Figure 2. ABCA1 inhibits the proliferation of colon cancer HCT116 cells. (A) Western blotting for ABCA1 in HCT116 cells. HCT116 cells were transfected with the ABCA1-expressing plasmids or empty vector (mock). $\beta$-actin was used as a loading control; $n=3$. (B) MTT assay of HCT116 cells. HCT116 cells were transfected with the ABCA1-expressing plasmids or empty vector (mock) and then cell viability was measured at the indicated time-points by MTT assay; $\mathrm{n}=3$. (C) BrdU incorporation assay of HCT116 cells transfected with the ABCA1-expressing plasmids or empty vectors (mock); n=3. (D) Western blotting for c-myc, p53, CDK2, p21, and cyclin D1 in the HCT116 cells transfected with the ABCA1-expressing plasmids or empty vector (mock). $\beta$-actin was used as a loading control; n=3. (E) Invasion and migration assays of HCT116 cells infected with the ABCA1-expressing plasmids or empty vector (mock); $n=3$.

Real-time PCR for miRNA. Total RNA was isolated from the cultured cells using the mirVana miRNA isolation kit (Ambion). Detection of the mature form of miRNAs was performed using the mirVana qRT-PCR miRNA detection kit (Ambion). The U6 small nuclear RNA was used as an internal control.

TUNEL staining. TUNEL staining analysis was performed as previously reported (37).

Statistical analysis. Data are presented as mean \pm SEM. Student's t-test (two-tailed) was used to compare two groups $(\mathrm{P}<0.05$ was considered significant), unless otherwise indicated $\left(\chi^{2}\right.$ test $)$.

\section{Results}

Aberrant expression of ABCAl in colon cancer tissues. In order to determine $\mathrm{ABCA} 1$ protein expression in colon cancer tissues, we performed western blot assay to detect ABCA1 protein in colon cancer tissues compared to the level in the adjacent normal tissues. We found that ABCA1 was decreased in the cancer tissues of 10 patients, when compared with that in the adjacent normal tissues (Fig. 1A). The data implied that ABCA1 may be a tumor-suppressive gene in colon cancer. In an attempt to identify the ABCA1 protein expression in the different colon cancer cell lines, we performed western blotting in DLD1, Caco-2, HCT116, DiFi, Lim1215 and HCA7 cells. ABCA1 protein varied in the different colon cancer cell lines (Fig. 1B).

Overexpression of $A B C A 1$ inhibits proliferation, but does not affect the migration and invasion of colon cancer HCT116 cells. In an attempt to determine whether ABCA1 regulates the proliferation of HCT116 cells, the cells were transfected with ABCA1-expressing plasmids. After stable transfection, ABCA1 expression was detected by western blotting. The results showed that the ABCA1-expressing plasmids evidently upregulated ABCA1 protein expression in the HCT116 cells (Fig. 2A). We next performed an MTT assay to detect the proliferation of the HCT116 cells transfected with the ABCA1expressing plasmid. The results showed that ABCA1 inhibited the proliferation of HCT116 cells after $48 \mathrm{~h}$ of transfection and the inhibition was dose-dependent (Fig. 2B). To further show the effects of ABCA1 on proliferation, we performed BrdU incorporation assay to detect DNA synthesis in the cells. The results confirmed that ABCA1 significantly inhibited DNA synthesis in the cells (Fig. 2C). In order to further identify the effect of ABCA1 on proliferation, we performed western blotting to confirm that ABCA1 could affect proliferation markers. The results of western blotting demonstrated that 
A

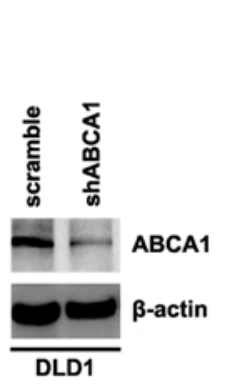

C

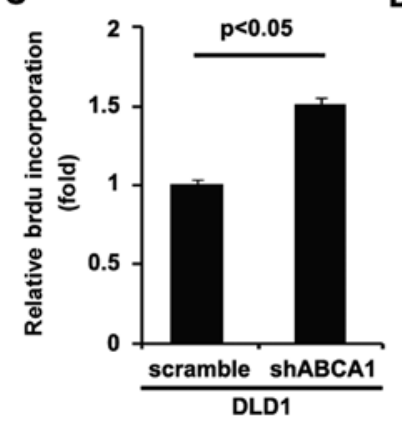

B

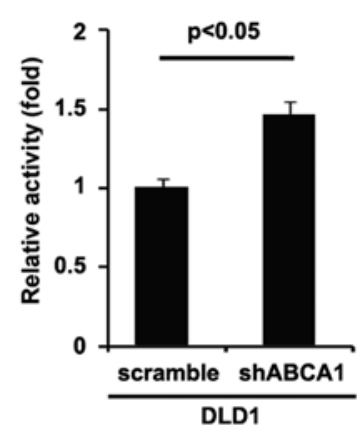

D

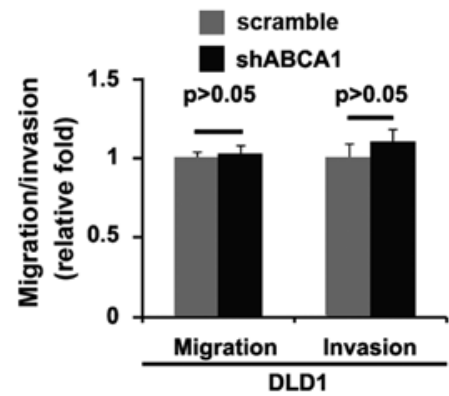

A
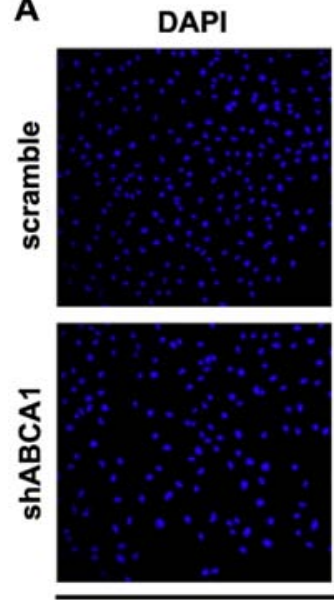

DLD1
TUNEL

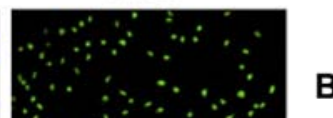

B
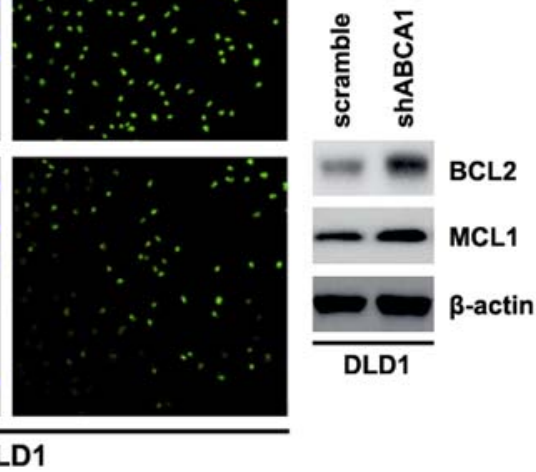

Figure 4. Silencing of ABCA1 inhibits the apoptosis of colon cancer LDL1 cells. (A) TUNEL assay for LDL1 cells transfected with shABCA1 and scramble; $n=3$. (B) Western blotting for BCL2 and MCL1 in the LDL1 cells transfected with shABCA1 and scramble. $\beta$-actin was used as a loading control; $n=3$.

Figure 3. Silencing of ABCA1 promotes the proliferation of colon cancer LDL1 cells. (A) Western blotting for ABCA1 in LDL1 cells. LDL1 cells were transfected with shABCA1 plasmids and scramble. $\beta$-actin was used as a loading control; $n=3$. (B) MTT assay of LDL1 cells. LDL1 cells were transfected with shABCA1 plasmids and scramble as indicated; $n=3$. (C) BrdU incorporation assay of LDL1 cells transfected with the shABCA1 plasmids and scramble; $n=3$. (D) Invasion and migration assays of LDL1 cells infected with the shABCA1 plasmids or scramble; $n=3$.

c-myc, CDK2 and cyclin D1 protein were downregulated and p53 and p21 were upregulated by ABCA1 in the HCT116 cells (Fig. 2D).

Given that ABCA1 obviously promotes HCT116 cell proliferation, we next sought to determine whether ABCA1 would have an impact on migration and invasion in the HCT116 cells. The migration and invasion assays showed that overexpression of ABCA1 did not affect the migration and invasion of the HCT116 cells (Fig. 2E).

Silencing of ABCA1 promotes proliferation, but does not affect migration and invasion in colon cancer DLDI cells. In order to further identify the role of ABCA1 in the regulation of the proliferation of colon cancer cells, DLD1 cells were transfected with shABCA1 plasmids. We found that ABCA1 protein was significantly decreased by the shABCA1 plasmids (Fig. 3A). After stable transfection, the proliferation rates of DLD1 cells were assessed by MTT assay. The results showed that silencing of ABCA1 significantly increased the proliferation rate of the DLD1 cells (Fig. 3B). This was further revealed by BrdU incorporation analysis showing that transfection with shABCA1 resulted in increased DNA synthesis activity per viable cell in the DLD1 cells (Fig. 3C).

Given that silencing of ABCA1 promotes DLD1 cell proliferation, we next sought to determine whether silencing of ABCA1 would have any impact on the migration and invasion in DLD1 cells. The migration and invasion assays of DLD1 cells showed that silencing of ABCA1 did not affect migration and invasion (Fig. 3D).

Silencing of ABCA1 inhibits apoptosis in colon cancer LDL1 cells. Having demonstrated that silencing of ABCA1 promotes the proliferation of LDL1 cells, to provide evidence that ABCA1 is involved in the regulation of apoptosis of LDL1 cells, we performed TUNEL assay to analyze whether silencing of ABCA1 affects the apoptosis in LDL1 cells. Through TUNEL assay, we observed a change in the apoptotic rate in the LDL1 cells transfected with shABCA1. Namely, silencing of ABCA1 inhibited the apoptosis of the LDL1 cells (Fig. 4A).

We also performed western blotting to identify whether protein levels of apoptosis-associated markers were also affected by shABCA1 in the cells. BCL2 and MCL1 are important anti-apoptotic molecules $(38,39)$. We showed that BCL2 and MCL1 expression levels were upregulated by silencing of ABCA1 in the cells (Fig. 4B).

miR-183 suppresses ABCA1 protein expression in the colon cancer cells. Having demonstrated that ABCA1 expression is specifically downregulated in colon cancer and it inhibits the proliferation of colon cancer cells, we aimed to ascertain the mechanisms involved in the inhibition of ABCA1 expression in colon cancer. MicroRNAs (miRNAs) are a new class of small ( 22 nucleotide) non-coding RNAs that negatively regulate protein-coding gene expression by targeting mRNA degradation or translation inhibition (22,40-44). Upregulation of specific miRNAs can contribute to tumor-suppressive gene downregulation (45). Thus, we hypothesized that ABCA1 is downregulated by overexpression of a specific miRNA in colon cancer.

To further confirm our hypothesis, we used a commonly used prediction algorithm - miRanda (http://www.microrna. org/microrna/home.do) to analyze the 3'UTR of ABCA1. The algorithm predicted that miR-183 may target the 3'UTR of ABCA1 (Fig. 5A). Thus, we reasoned that miR-183 could downregulate ABCA1 expression by targeting its 3'UTR in colon cancer and that ABCA1 was suppressed in colon cancer, due to the upregulation of miR-183 (32). 
A
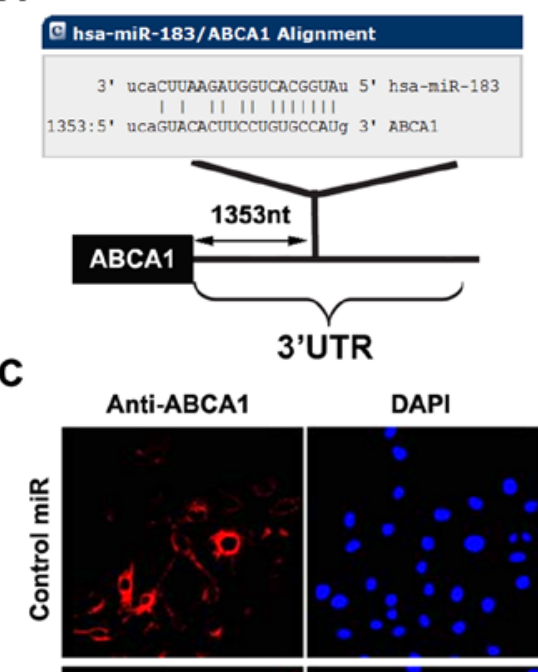

B
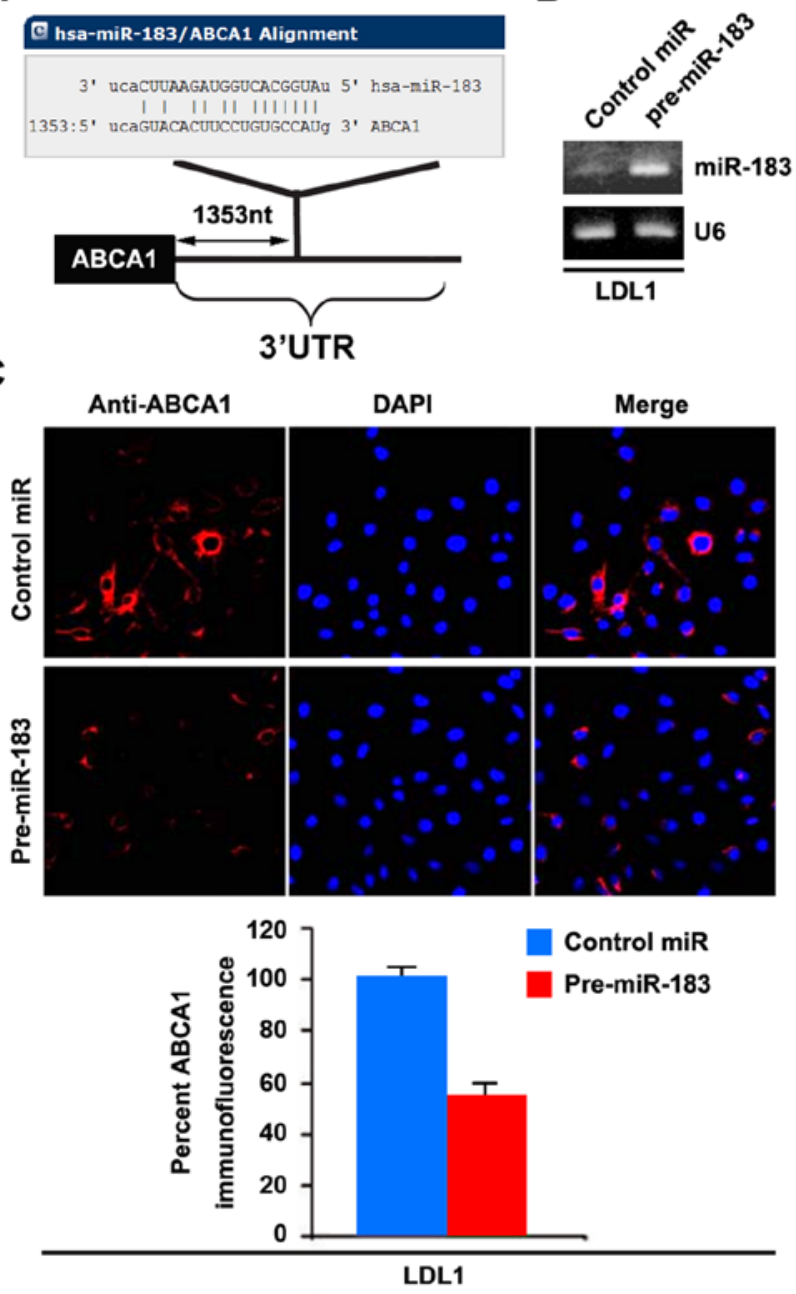

D
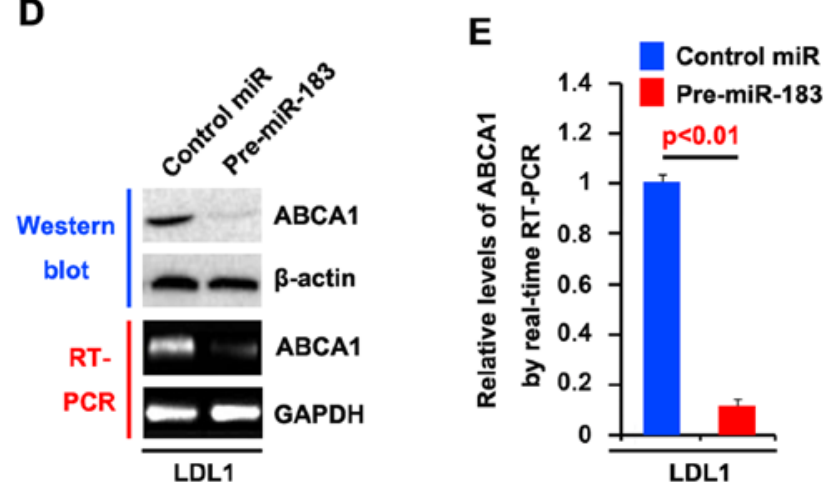

Figure 5. miR-183 degrades ABCA1 mRNA in colon cancer LDL1 cells. (A) Schematic of predicted miR-183-binding sites in the 3'UTR of ABCA1 mRNA by miRanda. (B) Real-time PCR for miR-183 in LDL1 cells. LDL1 cells were infected with pre-miR-183 or control miR (mock). U6 was used as a loading control; $n=3$. (C) Immunofluorescence analyses for LDL1 cells transfected with pre-miR-183 and control miR (mock). Upper panel shows microscopic images of immunofluorescence staining of one representative experiment (x100 magnifications). Bottom panel shows graphic presentation of mean fluorescence intensities; $n=3$. (D) Western blotting for ABCA1 protein in LDL1 cells infected as indicated. $\beta$-actin was used as a loading control. RT-PCR for ABCA1 mRNA in LDL1 cells infected as indicated. GAPDH was used as a loading control; $n=3$. (E) Real-time PCR for ABCA1 in LDL1 cells infected with pre-miR-183 or control miR (mock). GAPDH was used as a loading control; $n=3$.

In an attempt to identify the role of miR-183 in the regulation of ABCA1 expression in LDL1 cells, the cells were
A

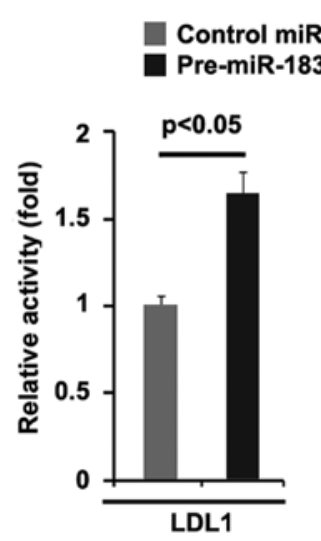

C
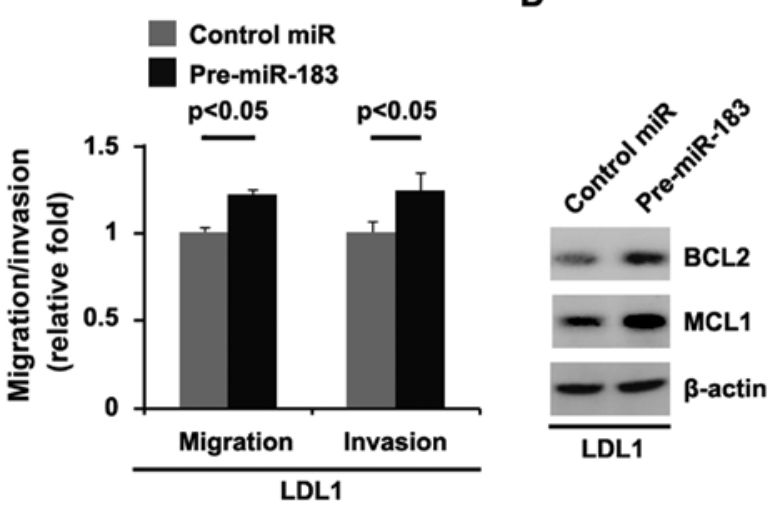

Figure 6. miR-183 promotes the proliferation and inhibits the apoptosis of colon cancer. (A) MTT assay of LDL1 cells. LDL1 cells were transfected with pre-miR-183 and control miR as indicated; $\mathrm{n}=3$. (B) BrdU incorporation assay of LDL1 cells transfected with pre-miR-183 and control miR; $\mathrm{n}=3$. (C) Invasion and migration assays of LDL1 cells transfected with premiR-183 or control miR; $n=3$. (D) Western blotting for BCL2 and MCL1 in LDL1 cells transfected with pre-miR-183 and control miR. $\beta$-actin was used as a loading control; $\mathrm{n}=3$.

transfected with pre-miR-183 and control miR. After transfection, miR-183 expression was detected by real-time PCR. The results showed that miR-183 was increased by pre-miR-183 in the cells (Fig. 5B).

We then performed immunofluorescence analyses in LDL1 cells transfected with pre-miR-183 or control miR. The results showed that ABCA1 protein was evidently suppressed in the cells transfected with pre-miR-183 (Fig. 5C). We next performed RT-PCR and western blotting to detect ABCA1 expression in LDL1 cells transfected with pre-miR-183 or control miR. The results showed that ABCA1 protein (Fig. 5D) and mRNA expression (Fig. 5D) were significantly downregulated in the cells transfected with pre-miR-183. Consistent with the results of RT-PCR, real-time PCR demonstrated that ABCA1 mRNA was reduced in the LDL1 cells transfected with pre-miR-183, compared with the control miR-transfected group (Fig. 5E). All the data demonstrated that miR-183 suppresses ABCA1 mRNA and protein expression in colon cancer cells.

miR-183 promotes the proliferation, migration and invasion of colon cancer DLD1 cells. In order to further identify the role of miR-183 in regulating the proliferation of DLD1 cells, the cells were transfected with pre-miR-183 and control miR. 
After stable transfection, the proliferation rates of the DLD1 cells were assessed by MTT assay. The results showed that miR-183 significantly promoted the proliferation rate of DLD1 cells (Fig. 6A). This was further revealed by BrdU incorporation analysis showing that transfection with pre-miR-183 resulted in increased DNA synthesis activity per viable cell in the DLD1 cells (Fig. 6B).

Given that miR-183 obviously promotes DLD1 cell proliferation, we next sought to determine whether miR-183 has any impact on the migration and invasion of DLD1 cells. The migration and invasion assays showed that miR-183 promoted the migration and invasion of the DLD1 cells (Fig. 6C).

We also performed western blot analysis to identify whether protein levels of apoptosis-associated markers were also affected by pre-miR-183 in the cells. Our studies showed that BCL2 and MCL1 expression levels were upregulated by pre-miR-183 in the cells (Fig. 6D).

\section{Discussion}

Colorectal cancer is the second leading cause of death by cancer worldwide (46). Western populations have a 1 in 20 lifetime risk of developing the disease and in many countries the rates are increasing (47). Despite major advances in our understanding of colon cancer, successful treatment remains dependent on early diagnosis and surgical intervention. Current oncological treatments such as radiotherapy and chemotherapy have relatively little impact on long-term survival and currently hope is pinned on screening to diagnose cancers and remove them even earlier. Yet, current population-based screening methods can only reduce colorectal cancer deaths by $20-30 \%$ (48) indicating that new approaches based on better understanding of the disease are needed before colorectal cancer can be added to the list of treatable or preventable malignancies.

Cholesterol is necessary for many functions in mammalian cells. Consequently, under normal conditions the intracellular cholesterol content is carefully regulated through processes of synthesis, uptake and efflux, with efflux carried out mainly by ABCA1 and ABCG1 (ATP-binding cassette transporters) (49,50). Deregulation of cholesterol homeostasis in human cancer is associated with the loss of ABCA1 (51). Yet, there is no report in colon cancer. For the first time, we demonstrated that ABCA1 protein was downregulated in colon cancer. Its overexpression inhibited proliferation while the silencing of ABCA1 promoted proliferation and inhibited apoptosis in colon cancer cells, implying that it is a tumorsuppressive gene in this disease.

Upregulation of specific miRNAs can contribute to downregulation of tumor-suppressive genes (33-35). Thus, we hypothesized that ABCA1 is downregulated by overexpression of a specific miRNA in colon cancer. Recently, it was reported that miR-183 is an oncogene in cancer (32). For example, the upregulation of miR-183 is associated with the onset and progression of hepatocellular carcinoma (HCC) (52). miR-183 was found to be an oncogene targeting Dkk-3 and SMAD4 in prostate cancer (53), and miR-183 functions as an oncogene by targeting the transcription factor EGR1 and promoting tumor cell migration in synovial sarcoma and colon cancer cell lines (32). In addition, miR-183 was found to inhibit TGF- $\beta 1$-induced apoptosis by downregulation of
PDCD4 expression in human HCC cells (54); The increased expression of miR-183 is closely related to advanced clinical stage, lymph node and distant metastases, and poor prognosis of colorectal cancer, indicating that miR-183 may serve as a predictive biomarker for the prognosis or the aggressiveness of colorectal cancer (55). Yet, the mechanism of miR-183 as an oncogene keeps emerging. We found that miR-183 promoted the proliferation and inhibited the apoptosis in colon cancer by targeting ABCA1. We observed that miR-183 promoted migration and invasion, while ABCA1 did not affect migration and invasion in colon cancer cells, implying that miR-183 may regulate migration and invasion through other target genes.

Recognition of the function of ABCA1 and its regulation in tumors will ultimately provide a better understanding of the signaling pathways that can be therapeutically modulated. Further investigation of the role of ABCA1 in colon cancer is warranted.

\section{References}

1. Ferlay J, Shin HR, Bray F, Forman D, Mathers C and Parkin DM: Estimates of worldwide burden of cancer in 2008: GLOBOCAN 2008. Int J Cancer 127: 2893-2917, 2010.

2. Dessí S, Batetta B, Anchisi C, Pani P, Costelli P, Tessitore L and Baccino FM: Cholesterol metabolism during the growth of a rat ascites hepatoma (Yoshida AH-130). Br J Cancer 66: 787-793, 1992.

3. Dessì S, Batetta B, Pulisci D, Spano O, Anchisi C, Tessitore L, Costelli P, Baccino FM, Aroasio E and Pani P: Cholesterol content in tumor tissues is inversely associated with high-density lipoprotein cholesterol in serum in patients with gastrointestinal cancer. Cancer 73: 253-258, 1994.

4. Kolanjiappan K, Ramachandran CR and Manoharan S: Biochemical changes in tumor tissues of oral cancer patients. Clin Biochem 36: 61-65, 2003.

5. Rudling M and Collins VP: Low density lipoprotein receptor and 3-hydroxy-3-methylglutaryl coenzyme A reductase mRNA levels are coordinately reduced in human renal cell carcinoma. Biochim Biophys Acta 1299: 75-79, 1996.

6. Schaffner CP: Prostatic cholesterol metabolism: Regulation and alteration. Prog Clin Biol Res 75A: 279-324, 1981.

7. Yoshioka Y, Sasaki J, Yamamoto M, Saitoh K, Nakaya S and Kubokawa M: Quantitation by (1)H-NMR of dolichol, cholesterol and choline-containing lipids in extracts of normal and phathological thyroid tissue. NMR Biomed 13: 377-383, 2000.

8. Järvinen R, Knekt P, Hakulinen T, Rissanen H and Heliövaara M: Dietary fat, cholesterol and colorectal cancer in a prospective study. Br J Cancer 85: 357-361, 2001.

9. Caruso MG, Notarnicola M, Santillo M, Cavallini A and Di Leo A: Enhanced 3-hydroxy-3-methyl-glutaryl coenzyme A reductase activity in human colorectal cancer not expressing low density lipoprotein receptor. Anticancer Res 19: 451-454, 1999.

10. Caruso MG, Notarnicola M, Cavallini A and Di Leo A: 3-Hydroxy-3-methylglutaryl coenzyme A reductase activity and low-density lipoprotein receptor expression in diffuse-type and intestinal-type human gastric cancer. J Gastroenterol 37: 504-508, 2002.

11. Notarnicola M, Messa C, Pricci M, Guerra V, Altomare DF, Montemurro S and Caruso MG: Up-regulation of 3-hydroxy3-methylglutaryl coenzyme A reductase activity in left-sided human colon cancer. Anticancer Res 24: 3837-3842, 2004.

12. Gregg RG, Davidson M and Wilce PA: Cholesterol synthesis and HMG CoA reductase activity during hepatocarcinogenesis in rats. Int J Biochem 18: 389-393, 1986.

13. Hentosh P, Yuh SH, Elson CE and Peffley DM: Sterol-independent regulation of 3-hydroxy-3-methylglutaryl coenzyme A reductase in tumor cells. Mol Carcinog 32: 154-166, 2001.

14. Siperstein MD: Cholesterol, cholesterogenesis and cancer. Adv Exp Med Biol 369: 155-166, 1995.

15. Graziani SR, Igreja FA, Hegg R, Meneghetti C, Brandizzi LI, Barboza R, Amâncio RF, Pinotti JA and Maranhão RC: Uptake of a cholesterol-rich emulsion by breast cancer. Gynecol Oncol 85: 493-497, 2002 
16. Schimanski S, Wild PJ, Treeck O, Horn F, Sigruener A, Rudolph C, Blaszyk H, Klinkhammer-Schalke M, Ortmann O, Hartmann A, et al: Expression of the lipid transporters ABCA3 and ABCA1 is diminished in human breast cancer tissue. Horm Metab Res 42: 102-109, 2010.

17. Tatidis L, Masquelier M and Vitols S: Elevated uptake of low density lipoprotein by drug resistant human leukemic cell lines. Biochem Pharmacol 63: 2169-2180, 2002.

18. Basso K, Margolin AA, Stolovitzky G, Klein U, Dalla-Favera R and Califano A: Reverse engineering of regulatory networks in human B cells. Nat Genet 37: 382-390, 2005

19. Ki DH, Jeung HC, Park CH, Kang SH, Lee GY, Lee WS, Kim NK, Chung HC and Rha SY: Whole genome analysis for liver metastasis gene signatures in colorectal cancer. Int J Cancer 121: 2005-2012, 2007.

20. Moustafa MA, Ogino D, Nishimura M, Ueda N, Naito S, Furukawa M, Uchida T, Ikai I, Sawada $H$ and Fukumoto $M$ : Comparative analysis of ATP-binding cassette (ABC) transporter gene expression levels in peripheral blood leukocytes and in liver with hepatocellular carcinoma. Cancer Sci 95: 530-536, 2004.

21. Attie AD: ABCA1: At the nexus of cholesterol, HDL and atherosclerosis. Trends Biochem Sci 32: 172-179, 2007.

22. Bartel DP: MicroRNAs: Genomics, biogenesis, mechanism, and function. Cell 116: 281-297, 2004.

23. Kim VN: Small RNAs: Classification, biogenesis, and function Mol Cells 19: 1-15, 2005.

24. Najafi-Shoushtari SH, Kristo F, Li Y, Shioda T, Cohen DE, Gerszten RE and Näär AM: MicroRNA-33 and the SREBP host genes cooperate to control cholesterol homeostasis. Science 328: $1566-1569,2010$.

25. Ramirez CM, Dávalos A, Goedeke L, Salerno AG, Warrier N, Cirera-Salinas D, Suárez Y and Fernández-Hernando C: MicroRNA-758 regulates cholesterol efflux through posttranscriptional repression of ATP-binding cassette transporter A1. Arterioscler Thromb Vasc Biol 31: 2707-2714, 2011

26. Ramírez CM, Rotllan N, Vlassov AV, Dávalos A, Li M, Goedeke L, Aranda JF, Cirera-Salinas D, Araldi E, Salerno A, et al: Control of cholesterol metabolism and plasma high-density lipoprotein levels by microRNA-144. Circ Res 112: 1592-1601, 2013.

27. Mendell JT: miRiad roles for the miR-17-92 cluster in development and disease. Cell 133: 217-222, 2008.

28. Lu J, Getz G, Miska EA, Alvarez-Saavedra E, Lamb J, Peck D, Sweet-Cordero A, Ebert BL, Mak RH, Ferrando AA, et al: MicroRNA expression profiles classify human cancers. Nature 435: 834-838, 2005.

29. Subramanian S, Lui WO, Lee CH, Espinosa I, Nielsen TO Heinrich MC, Corless CL, Fire AZ and van de Rijn M: MicroRNA expression signature of human sarcomas. Oncogene 27: 2015-2026, 2008.

30. Sarver AL, Phalak R, Thayanithy V and Subramanian S: S-MED: Sarcoma microRNA expression database. Lab Invest 90: 753-761, 2010.

31. Calin GA, Cimmino A, Fabbri M, Ferracin M, Wojcik SE, Shimizu M, Taccioli C, Zanesi N, Garzon R, Aqeilan RI, et al: miR-15a and miR-16-1 cluster functions in human leukemia. Proc Natl Acad Sci USA 105: 5166-5171, 2008.

32. Sarver AL, Li L and Subramanian S: MicroRNA miR-183 functions as an oncogene by targeting the transcription factor EGR1 and promoting tumor cell migration. Cancer Res 70: 9570-9580, 2010.

33. Meng F, Henson R, Wehbe-Janek H, Ghoshal K, Jacob ST and Patel T: MicroRNA-21 regulates expression of the PTEN tumor suppressor gene in human hepatocellular cancer. Gastroenterology 133: 647-658, 2007.

34. Zhu S, Wu H, Wu F, Nie D, Sheng S and Mo YY: MicroRNA-21 targets tumor suppressor genes in invasion and metastasis. Cell Res 18: 350-359, 2008.

35. Zhu S, Si ML, Wu H and Mo YY: MicroRNA-21 targets the tumor suppressor gene tropomyosin 1 (TPM1). J Biol Chem 282 : 14328-14336, 2007.

36. Wang XW, Xi XQ, Wu J, Wan YY, Hui HX and Cao XF: MicroRNA-206 attenuates tumor proliferation and migration involving the downregulation of NOTCH3 in colorectal cancer. Oncol Rep 33: 1402-1410, 2015.
37. Bekker-Méndez C, Guzmán-Aguilar RM, Hernández-Cueto MA Huerta-Yepez S, Jarillo-Luna RA, González-Veyrand E and González-Bonilla CR: TUNEL-positive cells in the surgical border of an amputation due to infected diabetic foot. Mol Med Rep 5: 363-372, 2012.

38. Ji F, Zhang H, Wang Y, Li M, Xu W, Kang Y, Wang Z, Wang Z, Cheng $\mathrm{P}$, Tong $\mathrm{D}$, et al: MicroRNA-133a, downregulated in osteosarcoma, suppresses proliferation and promotes apoptosis by targeting Bcl-xL and Mcl-1. Bone 56: 220-226, 2013.

39. Zhang H, Cai X, Wang Y, Tang H, Tong D and Ji F: microRNA-143, down-regulated in osteosarcoma, promotes apoptosis and suppresses tumorigenicity by targeting Bcl-2. Oncol Rep 24: $1363-1369,2010$

40. Lee RC, Feinbaum RL and Ambros V: The C.elegans heterochronic gene lin-4 encodes small RNAs with antisense complementarity to lin-14. Cell 75: 843-854, 1993 .

41. Pasquinelli AE, Reinhart BJ, Slack F, Martindale MQ, Kuroda MI, Maller B, Hayward DC, Ball EE, Degnan B, Müller P, et al: Conservation of the sequence and temporal expression of let-7 heterochronic regulatory RNA. Nature 408: 86-89, 2000.

42. Reinhart BJ, Slack FJ, Basson M, Pasquinelli AE, Bettinger JC, Rougvie AE, Horvitz HR and Ruvkun G: The 21-nucleotide let-7 RNA regulates developmental timing in Caenorhabditis elegans. Nature 403: 901-906, 2000.

43. Lewis BP, Burge CB and Bartel DP: Conserved seed pairing, often flanked by adenosines, indicates that thousands of human genes are microRNA targets. Cell 120: 15-20, 2005.

44. Farh KK, Grimson A, Jan C, Lewis BP, Johnston WK, Lim LP, Burge CB and Bartel DP: The widespread impact of mammalian microRNAs on mRNA repression and evolution. Science 310: 1817-1821, 2005.

45. Ma L, Young J, Prabhala H, Pan E, Mestdagh P, Muth D, Teruya-Feldstein J, Reinhardt F, Onder TT, Valastyan S, et al: miR-9, a MYC/MYCN-activated microRNA, regulates E-cadherin and cancer metastasis. Nat Cell Biol 12: 247-256, 2010.

46. Jemal A, Bray F, Center MM, Ferlay J, Ward E and Forman D: Global cancer statistics. CA Cancer J Clin 61: 69-90, 2011.

47. Center MM, Jemal A, Smith RA and Ward E: Worldwide variations in colorectal cancer. CA Cancer J Clin 59: 366-378, 2009

48. Heresbach D, Manfredi S, D'halluin PN, Bretagne JF and Branger B: Review in depth and meta-analysis of controlled trials on colorectal cancer screening by faecal occult blood test. Eur J Gastroenterol Hepatol 18: 427-433, 2006.

49. Oram JF and Lawn RM: ABCA1. The gatekeeper for eliminating excess tissue cholesterol. J Lipid Res 42: 1173-1179, 2001.

50. Kennedy MA, Barrera GC, Nakamura K, Baldán A, Tarr P, Fishbein MC, Frank J, Francone OL and Edwards PA: ABCG1 has a critical role in mediating cholesterol efflux to HDL and preventing cellular lipid accumulation. Cell Metab 1: 121-131, 2005.

51. Solomon KR, Allott EH, Freeman MR and Freedland SJ: Words of wisdom. Re: Dysregulation of cholesterol homeostasis in human prostate cancer through loss of ABCA1. Eur Urol 63: 1128-1129, 2013.

52. Liang Z, Gao Y, Shi W, Zhai D, Li S, Jing L, Guo H, Liu T, Wang Y and Du Z: Expression and significance of microRNA-183 in hepatocellular carcinoma. ScientificWorldJournal 2013: 381874 , 2013.

53. Ueno K, Hirata H, Shahryari V, Deng G, Tanaka Y, Tabatabai ZL, Hinoda Y and Dahiya R: microRNA-183 is an oncogene targeting Dkk-3 and SMAD4 in prostate cancer. Br J Cancer 108: 1659-1667, 2013

54. Li J, Fu H, Xu C, Tie Y, Xing R, Zhu J, Qin Y, Sun Z and Zheng X: miR-183 inhibits TGF-beta1-induced apoptosis by downregulation of PDCD4 expression in human hepatocellular carcinoma cells. BMC Cancer 10: 354, 2010.

55. Zhou T, Zhang GJ, Zhou H, Xiao HX and Li Y: Overexpression of microRNA-183 in human colorectal cancer and its clinical significance. Eur J Gastroenterol Hepatol 26: 229-233, 2014. 